\title{
Z-transform theory in general array analysis
}

\section{Christiansen, Peter Leth}

\section{Published in:}

I E E E Transactions on Antennas and Propagation

Publication date:

1964

\section{Document Version}

Publisher's PDF, also known as Version of record

Link back to DTU Orbit

Citation (APA):

Christiansen, P. L. (1964). Z-transform theory in general array analysis. I E E E Transactions on Antennas and Propagation, 12(5), 647.

\section{General rights}

Copyright and moral rights for the publications made accessible in the public portal are retained by the authors and/or other copyright owners and it is a condition of accessing publications that users recognise and abide by the legal requirements associated with these rights.

- Users may download and print one copy of any publication from the public portal for the purpose of private study or research.

- You may not further distribute the material or use it for any profit-making activity or commercial gain

- You may freely distribute the URL identifying the publication in the public portal

If you believe that this document breaches copyright please contact us providing details, and we will remove access to the work immediately and investigate your claim 
The occurrence of $k_{0} b$ to the inverse second power in formula (10) is a consequence of the fact that the quasi-static electric field is almost entirely responsible for the ohmic heating losses, and that this field is proportional to $r^{-3}$ for the electric dipole and $r^{-2}$ for the magnetic dipole. In a recent paper Galejs? examined the relative ohmic losses for small capacitor type and loop antennas constructed on spherical cores of conducting dielectric. He found that the relative core losses for the two types are proportional to $\left(k_{0} b\right)^{-2}$ for of course the same reason as advanced above.

The simple formulas for $\eta^{s, m}$ hold only when $\omega \epsilon_{0} / \sigma_{2} \ll 1$ and $k_{0} b \ll 1$; hence for values of $b / d$ such that $\eta^{e, m}$ is substantially less than unity the input power to these antennas will be very nearly equal to the power dissipated. Under these conditions $\eta^{e, m}$ can be taken as the radiation efficiency of the electric or magnetic dipole surrounded by a shell of lossy dielectric.

By equating $\eta^{2}$ and $\eta^{m}$ for the same size shell but different conductivities, the results of this paper and those of Galejs show that for a given radiation efficiency it is possible to tolerate a much higher conductivity dielectric in the near zone of a small magnetic type antenna than with an electric type.

RoNald V. Row

Applied Research Lab.

Sylvania Electronic Systems

A Div. of Sylvania Electric Products Inc. Waltham, Mass.

2 J. Galejs, "Small electric and magnetic antennas with cores of a lossy dielectric, $J$. Research $N^{\prime} a l l$. Bur. Stds., vol. 67D, p. 445; July-August, 1963.

\section{$Z$-Transform Theory in General Array Analysis}

In a recent communication ${ }^{1}$ Cheng has stated that arrays with nonuniform spacing can be studied by means of a complex envelope function. In this communication the array factor $G(\theta, \phi)$ for an arbitrary array with $n$ elements is written as a $Z$ transform, and the usefulness of $Z$-transform theory in general array analysis is discussed.

Let the real vector envelope function for the positions of the elements and the complex scalar envelope function for the currents on them, be defined as

$$
\bar{r}(x)=x \hat{\xi}+\bar{s}(x)
$$

and

$$
\begin{aligned}
\sigma(x)= & A(\bar{r}(x)) \\
& \cdot \exp \left(j\left[\frac{\alpha}{d} \bar{r}(x) \cdot \hat{\xi}+\phi(\bar{r}(x))\right]\right)
\end{aligned}
$$

Manuscript received April 6, 1964.

${ }^{1} \mathrm{D}$. K. Cheng, ${ }^{4} Z$-transform theory for linear array analysis," IEEE TRANS. ON ANTENNAS AND PROPAGATION (Commun.), vol. AP-11, p. 593; September, 1963.

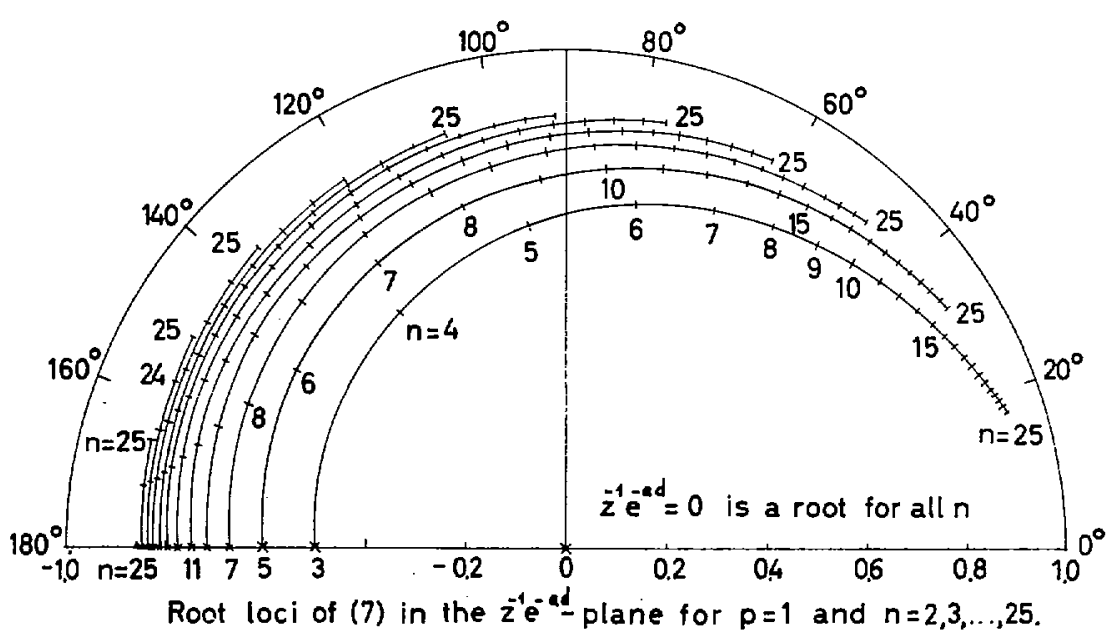

$f$ complex root (the complex conjugate roots are not shown). * real root.

Fig. 1.

respectively, where $x=\nu d$ on the $\nu$ th element, $\bar{s}(x)$ and $\phi(\bar{r}(x))$ are nonlinear functions of $x$ and $\bar{r}$, respectively, and $A(\bar{r}(x))$ is the amplitude of $\sigma(x) . \hat{\xi}=(1,0,0)$ and

$\hat{R}=\hat{\xi} \sin \theta \cos \phi+\hat{\eta} \sin \theta \sin \phi+\hat{\zeta} \cos \theta$.

If $\bar{s}(x) \equiv 0, d$ is the distance between the elements and $\alpha$ is the linear phase progression. We then obtain

$$
\begin{aligned}
G(\theta, \phi)= & \sum_{\nu=0}^{n-1} A(\bar{r}(\nu d)) \\
& \cdot \exp \left(j\left[\frac{\alpha}{d} \bar{r}(\nu d) \cdot \hat{\xi}+\phi(\bar{r}(\nu d))\right]\right) \\
& \cdot \exp [j k \bar{r}(\nu d) \cdot \hat{R}] \\
= & Z\{A(\bar{r}(x)) \exp (j[\phi(\bar{r}(x)) \\
& \left.\left.\left.+\left(\frac{\alpha}{d} \hat{\xi}+k \hat{R}\right) \cdot \bar{s}(x)\right]\right) \gamma_{n}(x)\right\}
\end{aligned}
$$

where $k$ is the propagation constant, $\gamma_{n}(x)$ is the unit gate function, ${ }^{2}$ and the following transformation ${ }^{3}$ has been used:

$$
\exp \{j[\alpha+k d \hat{\xi} \cdot \hat{R}]\}=z^{-1}
$$

In (4) the array factor is written as a polynomial of $(n-1)$ th degree in $z^{-1}$. Only two classes of polynomials in which the number of terms depends on the degree appear to have been given in a closed form (i.e., a form in which the number of terms does not depend on the degree):

1) Polynomials where new roots do not enter when the degree is increased beyond a certain value, e.g., the binomial distribution ${ }^{4}$

$$
\left(1-z^{-1}\right)^{n-1}=Z\left\{\frac{1}{\frac{x}{d} B\left(\frac{x}{d}, \frac{n d-x}{d}\right)}\right\}
$$

2 P. L. Christiansen, "On the closed form of the array factor for linear arrays," IEEE TRANS. ON ANTENNAS AND PROPAGATION (COmmun.), vol. AP-11, p. 198; March, 1963.

3 S. A. Schelkunoff, "A mathematical theory of inear arrays," Bell Sys. Tech. J., vol. 22, pp. 80-107; January, 1943

John Stone Stone, U. S. Patents 1,643,323 and $1,715,433$. in which $B$ denotes Euler's beta function, and the unit gate function does not appear explicitly. In general, however, it is difficult to give analytical expressions for the envelope functions and $Z$-transform theory is not helpful. This is also the case when the principle of pattern multiplication ${ }^{b}$ is applied.

2) Polynomials which can be obtained from the formula

$$
\begin{aligned}
& Z\left\{(\omega x)^{p} e^{-a x} \gamma_{n}(x)\right\} \\
& =(-\omega)^{p} \frac{\partial^{p}}{\partial a^{p}} \frac{1-e^{-a n d_{z}-n}}{1-e^{-a d_{z}-1}}
\end{aligned}
$$

which is given in a previous communication ${ }^{2}$ and derived in a report ${ }^{6}$ by means of $Z$-transform theory. In this case new roots enter in an interesting way when $n$ is increased. For $p=0$ they will all lie on the circle $\left|e^{-a d_{z}} z^{-1}\right|=1 ;\left(e^{-a d_{z}}{ }^{-1} \neq 1\right)$. For $p=1$ all roots will lie inside the circle $e^{-a d_{Z}-1}=1$ (this case is shown in Fig. 1 for $n=2,3, \cdots, 25$ ). The root configuration for higher values of $p$ can be studied by means of the Schur-Cohn criterion. ${ }^{?}$

We have thus considered coefficients and roots in the two classes of polynomials which can be given in a closed form. $Z$-transform theory was only relevant in the second class. Also, since very special requirements must be placed on the position and the current envelope functions before (7) can be applied to (4), severe limitations are imposed on the applicability of $Z$-transform theory in obtaining a closed form for the array factor in general array analysis.

Peter L. Christiansen L,ab. of Electromagnetic Theory Technical University of Denmark Copenhagen, Denmark

"J. D. Kraus, "Antennas," McGraw-Hill Book Co., Inc, New York, N. Y., p. 94; 1950.

${ }^{6} \mathrm{P} . \mathrm{L}$. Christiansen, "List of Z-transforms," R 32 Lab, of Electromagnetic Theory, The Technical University of Denmark, Copenhagen, pp. 5-7; July, 1963

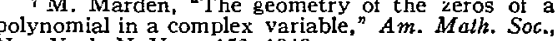
polynomial in a complex variable
New York, N. Y.., p. 152; 1949. 